\title{
A educação de jovens e adultos Após 20 vinte anos da Lei no 9.394, de 1996
}

\author{
Maria Margarida Machado*
}

RESUMO: $\mathrm{O}$ artigo apresenta reflexões sobre a educação de jovens e adultos (EJA), após 20 anos de implantação da Lei no 9.394, de 1996, analisando impactos e identificando rupturas e permanências no cenário da educação, com foco na escolarização de jovens e adultos trabalhadores, se alicerçando em contribuições de outros autores, em pesquisa documental e em dados estatísticos, produzidos por órgãos governamentais, na tentativa de provocar um diálogo entre os que atuam e pensam sobre a EJA.

Palavras-Chave: Educação de jovens e adultos trabalhadores. LDB. Educação como direito.

\section{Youth and adult education}

After 20 years of Law no 9.394 of 1996

\begin{abstract}
The article presents reflections on youth and adult education (EJA), after 20 years of implementation of Law n⿳ 9394, de 1996, analyzing impacts and identifying ruptures and permanences in the education scene, focusing on the schooling of young and adult workers. It is based on contributions from other authors, documentary research and statistical data produced by government agencies, in an attempt to provoke a dialogue between those who act on and think about the EJA.
\end{abstract}

Key words: Education of young and adult workers. Legal guidelines and bases for education (LDB). Education as a right.

* Doutora em Educação. Realiza estágio Pós-Doutoral na Universidade de Sevilha na Espanha. Atualmente é professora associada da Universidade Federal de Goiás, na Faculdade de Educação. Goiânia/GO - Brasil. E-mail: <mmm2404@gmail.com>. 


\section{La educación de jóvenes y adultos}

20 años después de la Ley nº 9.394, de 1996

RESUMEN: El artículo presenta reflexiones sobre la educación de jóvenes y adultos (EJA) 20 años después de implantación de la Ley no 9.394, de 1996, analizando sus efectos e identificando rupturas y permanencias en el escenario de la educación. El foco se centra en la escolarización de jóvenes y adultos trabajadores y se toman como base contribuciones de otros autores, fuentes documentales y datos estadísticos producidos por órganos gubernamentales, con la intención de promover un diálogo entre los que actúan y piensan sobre EJA.

Palabras clave: Educación de jóvenes y adultos trabajadores. LDB. Educación como derecho.

\section{L'éducation des jeunes et des adultes}

Aprés 20 ans de la Loi no 9.394, de 1996

RÉSUMÉ: Cet article présente des réflexions sur l'éducation des jeunes et des adultes(EJA), aprés 20 ans de mise en oeuvre de la Loi no 9394, de 1996, en analysant les impacts et en identifiant les ruptures et les continuités dans le cadre de l'éducation, avec un accent mis sur la scolarisation des jeunes et des adultes travailleurs, et ce en se basant sur les contributions d'autres auteurs, sur de la recherche documentaire et sur des données statistiques, produites par des organismes gouvernementaux, afin de provoquer un dialoque entre ceux qui jouent un rôle dans l' EJA et ceux qui la pensent.

Mots-clés: Education de jeunes et adultes travailleurs. LDB. Education comme droit. 


\section{Introdução}

É

um desafio, para quem é da área de História, realizar um balanço de 20 anos de qualquer política, ainda mais quando se trata de uma normativa no campo educacional. Temos sempre a impressão de que é um tempo muito curto para analisar impactos, identificar rupturas e permanências no cenário da educação e seus desdobramentos na conjuntura social como um todo. Todavia, nos desafiamos a fazê-lo, tendo a clareza de que as reflexões aqui apresentadas devem ser tomadas como aproximações possíveis, do olhar de quem viveu e vive, intensamente, os acontecimentos desses vinte anos analisados.

Um duplo desafio por ter que iniciá-lo expressando perplexidade com o que ocorre hoje no Brasil. Vivemos meses difíceis na nossa história, consternados por fatos evidentes de uma crise ética e política: estamos em pleno golpe de Estado, onde o Congresso Nacional afasta/retira/cassa o mandato da Presidenta Dilma, sem fundamento legal para isso; esse mesmo Congresso conservador defende como principal bandeira para educação o discurso de "Uma Escola Sem Partido"; está em curso a privatização em todos os níveis de educação, pela legalização das chamadas organizações sociais (OS); é cada vez mais evidente a negação do direito e respeito às diversidades, justificadas por um moralismo xenofóbico que avança no País. Não estamos isolados, essa conjuntura se soma ao que está ocorrendo em grande parte dos países latino-americanos emergentes, que tentam retomar a educação emancipatória na reconstrução democrática, em cada um deles, e, por isso, vêm sendo "golpeados" (Honduras, Paraguai) e ameaçados (Venezuela, Bolívia, Equador), com o ascenso do neoliberalismo conservador (Argentina) ou seu retorno eminente.

Nessa conjuntura, um balanço de 20 anos da aprovação da Lei de Diretrizes e Bases da Educação Nacional (LDB) no 9.394, de 1996 (BRASIL, 1996a), pensando especificamente o campo da educação de jovens e adultos (EJA), necessita explicitar teórica e politicamente de que concepção de educação tratamos. Não cabe realizar uma aprofundada reconstituição histórica, voltada a cada aspecto normativo decorrente da aprovação da Lei, porque ao longo desse texto indicaremos várias referências em que isto já está feito. Todavia reafirmamos a compreensão de que estamos falando de educação como prática humana, constituída e constituinte das relações sociais e políticas produzidas no âmbito da sociedade. Educação como direito de todas e todos os cidadãos a acessarem democraticamente os saberes sistematizados pela humanidade, contribuindo na construção de novos saberes. Educação garantida como política pública de Estado, pois essa é a única alternativa possível para que os trabalhadores e as trabalhadoras deem prosseguimento a seus estudos.

O objetivo do texto é provocar um diálogo entre os que atuam na EJA, a partir de reflexões e indagações que nos ocorrem, quando paramos para pensar 20 anos atrás, 
mas sobretudo quando nos comprometemos em seguir construindo 20 anos para frente. Esse é o verdadeiro sentido de qualquer balanço: olhar para frente, partindo de uma análise sincera do que foi feito, mas sobretudo assumindo o que ainda está por ser feito.

Outra questão relevante é que tratamos o tema da EJA sob o olhar da legislação atual no Brasil, portanto, estamos falando de escolarização. Cabe ressaltar, todavia, que a EJA não se reduz a escolarização. Sua história, na realidade brasileira, e também na realidade latino-americana, abarca a luta pelo direito de acesso, permanência e conclusão da escolarização com qualidade, em consonância com inúmeras outras lutas: pelos direitos à saúde, ao trabalho, à moradia digna (seja no campo ou nas cidades), à igualdade de gênero, ao respeito às diversidades, dentre tantas outras, que a configuram como educação ao longo de toda a vida e pela construção de uma sociedade que, de fato, seja espaço de vivência e convivência de todas e todos.

Tendo em mente estas considerações, o propósito deste artigo está reduzido a um aspecto da EJA, que é sua presença na política educacional brasileira, que será analisada utilizando como "lente" a legislação pertinente, considerando a Lei algo "vivo". Como o próprio pensador Jamil Cury (2002) destaca,

\footnotetext{
[...] a importância da lei não é identificada e reconhecida como um instrumento linear ou mecânico de realização de direitos sociais. Ela acompanha o desenvolvimento contextuado da cidadania em todos os países. A sua importância nasce do caráter contraditório que a acompanha: nela sempre reside uma dimensão de luta. Luta por inscrições mais democráticas, por efetivações mais realistas, contra descaracterizações mutiladoras, por sonhos de justiça. (p. 247)
}

Assim como consideramos uma lei resultado de uma luta histórica, também consideramos a escola como uma conquista da humanidade. Por esse motivo, ao lado de todas as lutas travadas na EJA, a luta pelo direito a escolarização de qualidade é uma bandeira que precisa ser retomada em seu sentido mais profundo, como um compromisso ético-político dos educadores para com os educandos. Digo isto porque há, sobretudo nas últimas décadas, uma perda do sentido da escola como um espaço de aprender e ensinar, de acessar e produzir conhecimento, de aguçar o potencial do pensamento crítico e reflexivo. Para todas as gerações isto é um grande prejuízo, mas para jovens e adultos trabalhadores resulta na inviabilidade de seu retorno ao processo de escolarização, pois se perde o sentido da luta pelo acesso à escola, já que esta não consegue cumprir seu principal papel, que é o de produzir e lidar com o conhecimento transformador da realidade de desigualdades sociais numa perspectiva emancipatória dos trabalhadores.

Esse debate, portanto, sobre a presença da EJA numa lei nacional, como ela vai ser considerada, que impactos essa lei nacional vai gerar ou não sobre as leis estaduais ou municipais, de fato, só faz sentido se formos capazes de precisar de que escola estamos falando para os jovens e adultos trabalhadores. Há modelos de escola e concepções de formação em disputa e, mais do que a presença ou não na legislação, ao analisar os 20 
anos pós-LDB, de 1996, cabe explicitar de que concepções e modelos estamos falando e quais, de fato, prevaleceram no arcabouço legal.

Assim como definimos lei como espaço de luta, entendemos que, na EJA, não cabe outra senão a perspectiva de uma escola emancipatória, que considera o conhecimento como um dos componentes fundantes da consciência crítica. Embora isto esteja muito distante da nossa realidade, consideramos ser o horizonte formativo a ser perseguido e, para isso, convidamos os leitores a responder a pergunta abaixo.

[...] é preferível 'pensar' sem disto ter consciência crítica, de uma maneira desagregada e ocasional, isto é 'participar' de uma concepção de mundo 'imposta' mecanicamente pelo ambiente exterior, ou seja, por um dos muitos grupos sociais nos quais todos estão automaticamente envolvidos desde sua entrada no mundo consciente (e que pode ser a própria aldeia ou província, pode se originar na paróquia e na 'atividade intelectual' do vigário ou do velho patriarca, cuja 'sabedoria' dita leis, na mulher que herdou a sabedoria das bruxas ou no pequeno intelectual avinagrado pela própria estupidez e pela impotência para a ação), ou é preferível elaborar a própria concepção de mundo de uma maneira consciente e crítica e, portanto, em ligação com este trabalho do próprio cérebro, escolher a própria esfera da atividade, participar ativamente na produção da história do mundo, ser o guia de si mesmo e não mais aceitar do exterior, passiva e servilmente, a marca da própria personalidade? (GRAMSCI, 1999, p. 93-94)

Essa questão nos toca a todas e todos, educadores, educandos, gestores, pesquisadores, militantes nas várias frentes, que envolvem a busca pela garantia dos direitos para jovens e adultos trabalhadores. No caso de uma reflexão sobre os 20 anos da LDB, de 1996, nos parece ser oportuno refletir se nossa postura frente a sua constituição histórica, implantação e implementação se deu "de uma maneira desagregada e ocasional" ou de maneira "consciente e crítica". A mesma pergunta vale para como lidamos hoje com esta lei, pois como ela é "viva" ainda está em construção.

Para tentar contribuir com estas reflexões é que falamos de "dentro da história" para pensar a sua continuidade, e processamos o trabalho do "próprio cérebro" organizando esta reflexão em três partes: a primeira analisa a EJA na LDB, de 1996 na sua relação com um passado que não passou, ou seja, se chegamos a uma redação específica nesta última Lei de Diretrizes e Bases da Educação Nacional, há algo de passado e processo que precisa ser compreendido. A segunda parte dialoga com os movimentos internos e externos vividos pela EJA, envolvendo sociedade civil e governos, para identificar o papel assumido no conjunto das políticas educacionais implementadas nesses 20 anos. A última parte do artigo, dialogando com a questão colocada nessa introdução, lança mão de outras reflexões, mais próprias para um diálogo entre educadores, que atuam na EJA em seus diferentes espaços, expressando as dúvidas e angústias de quem quer seguir pensando a construção dos próximos 20 anos, por não abrir mão do "otimismo da vontade" ${ }^{11}$, todavia sem desconsiderar o "pessimismo da inteligência" que cerca grande parte de nós educadores nos últimos tempos. 


\section{EJA: um passado ainda presente}

Os professores da EJA que iniciaram sua atuação na educação básica, nos anos 1980, devem se lembrar de que, na maioria dos estados brasileiros, a oferta do Mobral $^{2}$ e das classes de Ensino Supletivo ${ }^{3}$ era de acesso restrito para os professores, pois para o primeiro eram recrutados monitores e, para o segundo, dependendo da demanda, eram feitos contratos temporários de professores. As políticas oficiais de educação de adultos deixaram marcas muito significativas no imaginário da população, que até hoje ainda podem ser identificadas, sobretudo com um tratamento pejorativo, chamando de "mobral" ou "supletivo" às pessoas que tem pouco conhecimento sobre qualquer coisa.

Mas, não temos apenas esta lembrança dos vinte e um anos de Ditadura Militar. Sabemos que, antes do Golpe de 1964, o Brasil vivia um intenso processo político e social, que apontava para necessidades e possibilidades de mudanças no País, sobretudo com as pressões exercidas sobre o Governo João Goulart para que implantasse as chamadas Reformas de Base. Desta memória vem uma outra concepção de educação de adultos, que nasceu no seio dos movimentos populares e estudantis, das décadas de 1950 e 1960", e quase foram silenciadas pela repressão dos 21 anos de ditadura no País.

Destaco as duas referências: políticas governamentais e experiências populares de educação de adultos para chegar ao cenário que possibilitou a aprovação da Lei nº 9.394, de 1996, que precisa ser compreendida, no campo da EJA, por disputas conceituais. Ou seja, para analisar a LDB, de 1996, 20 anos após sua aprovação, é necessário compreender, pelo menos 20 anos ou um pouco mais, que antecederam sua aprovação. Isto porque o final da Ditadura Militar, em 1985, e a chamada redemocratização do País, que se estende até a aprovação da Constituição Federal de 1988, não rompem com as disputas inerentes ao que se defendeu por educação de adultos, antes do golpe, e se praticou como educação de adultos durante a ditadura.

Portanto, mesmo reconhecendo os avanços na área da educação em geral, se pensarmos o debate do texto aprovado da CF de 1988, é necessário perceber que muitas das tradições enraizadas no pensamento brasileiro sobre a quem se destina a educação e como ela deve ser praticada contradizem com a defesa central desta constituição, que é a Educação como Direito de Todos. Isto é muito evidente para quem acompanha a luta histórica do direito a educação para jovens e adultos trabalhadores no Brasil. Nesse sentido, há um passado que não passou, que é o do preconceito com pobres, negras e negros, população que vive no campo ou nas periferias das cidades, que são a maioria daqueles que ainda não concluíram a educação básica, mesmo já tendo passados mais de duas décadas da aprovação da CF de 1988.

Desse passado que ainda não passou cabe destacar a visão ainda muito marcada, nas ofertas escolarizadas da EJA, por propostas aligeiradas de ensino fundamental e médio, com uma clara herança das experiências de campanhas, turmas do Mobral e 
organização de classes de suplência. Em grande parte, o que estas experiências defendiam era que se precisava reduzir tempo e conteúdo para que o aluno "terminasse logo" o que vinha fazer, porque ele tinha pressa e o mercado de trabalho que o esperava, também. O argumento não é de todo falso, em geral, jovens e adultos que retornam a escola, de fato, não querem perder tempo, todavia a questão que se coloca é: mas o que é mesmo ganhar tempo? É sair de um processo de escolarização o quanto antes, não importa se o conhecimento foi ou não acessado e produzido ali, apenas ter um certificado? Com essas indagações voltamos à segunda parte do argumento: será mesmo que o mercado de trabalho, há vinte anos e, sobretudo hoje, emprega trabalhadores apenas porque têm um certificado para apresentar?

Essa visão, infelizmente, ainda se reproduz nas atuais escolas de EJA. Mas, diria que há algo ainda mais perverso que iludir a população com a certificação fácil. Trata-se de corromper o verdadeiro sentido da escola e seu papel na transformação da realidade. Isso, de fato, herdamos de um passado que não passou. E nos remete à questão já colocada, das concepções em disputa da EJA, pois se nos reportarmos aos movimentos populares de educação, da primeira metade da década de 1960, recordamos ali a defesa de uma visão emancipatória de educação, para usar um termo freiriano, e que ainda luta bravamente para se manter viva no meio dos educadores brasileiros.

Outra evidência do passado que não passou está no processo de debate e de elaboração da LDB, de 1996, que evidencia as disputas conceituais travadas entre o texto aprovado pela Câmara dos Deputados em 1993 e a redação da Lei nº 9.394, de 1996, como pode ser evidenciado no quadro que segue.

\section{Quadro 1 - Comparativo entre o PL no 101, de 1993 e a Lei no 9.394, de 1996}

\section{Projeto de Lei $\mathrm{n}^{\mathrm{o}}$ 101, de 1993 (no 1.258 , de 1988 na casa de origem)*}

Capítulo III

DO DIREITO A EDUCAÇÃO E DO DEVER DE EDUCAR

Art. $4^{\circ} \mathrm{O}$ dever do Estado com a educação escolar pública será efetivado mediante a garantia de:

I - universalização da educação básica, em todos os seus níveis e modalidades, através de:

a) atendimento em creches e pré-escolas às crianças de zero a seis anos de idade, nos termos dos arts. 7", XXV, 30, VI, 208, IV e 227 da Constituição Federal;

b) oferta de ensino gratuito fundamental e médio, inclusive para os que a ele não tiveram acesso na idade própria, vedada a cobrança, a qualquer título, de taxas escolares ou outras contribuições dos alunos;

c) cumprimento da obrigatoriedade imediata no ensino fundamental e da sua progressiva extensão ao ensino médio, nos termos da Constituição Federal, desta Lei e dos planos nacionais de educação;

II - oferta de ensino noturno regular, nos níveis fundamental, médio e superior, no mesmo padrão de qualidade do ensino diurno; 


\section{Projeto de Lei $\mathrm{n}^{\mathrm{0}}$ 101, de 1993 ( $\mathrm{n}^{\mathrm{0}} 1.258$, de 1988 na casa de origem)*}

III - oferta de educação escolar regular para jovens e adultos com características e modalidades adequadas às suas necessidades e disponibilidades, garantindo-se aos que forem trabalhadores as condições de acesso e permanência na escola;

(...)

\section{Capítulo XII}

\section{DA EDUCAÇÃO BÁSICA DE JOVENS E ADULTOS TRABALHADORES}

Art. 56. A educação básica pública oferecerá alternativas adequadas às necessidades da população trabalhadora, jovem e adulta, e será regulada pelo respectivo sistema de ensino.

Parágrafo Único - As alternativas referidas neste Artigo, incluirão, no mínimo:

I - disponibilidade de aparelhagem e demais condições para recepção de programas de teleducação (sic) no local de trabalho, em empresas e órgãos públicos com mais de 100 (cem) empregados;

II - oferta regular de ensino noturno, entendido como tal o oferecido a partir das dezoito horas, nos mesmos padrões de qualidade do diurno, e em escola próxima dos locais de trabalho e residência;

III - alternativas de acesso a qualquer série ou nível, independentemente de escolaridade anterior, sem restrições de idade máxima, mediante avaliação dos conhecimentos e experiências, admitida, quando necessária. a prescrição de programas de estudos complementares em paralelo;

IV - conteúdos curriculares centrados na prática social e no trabalho e metodologia de ensino-aprendizagem adequada ao amadurecimento e experiência do aluno;

V - organização escolar flexível, inclusive quanto à redução da duração da aula e do número de horas-aula, à matrícula por disciplina e a outras variações envolvendo os períodos letivos, a carga horária anual e o número de anos letivos dos cursos;

VI - professores especializados;

VII - programas sociais de alimentação, saúde, material escolar e transporte, independentemente do horário e da modalidade de ensino, financiados com recursos específicas;

VIII - outras formas e modalidades de ensino, que atendam as demandas dessa clientela, nas diferentes regiões do país.

Art. 57. O Poder Público viabilizará e estimulará o acesso e a permanência do trabalhador na escola, mediante ações integradas e complementares entre si, que incluirão:

I - ações junto dos empregadores, mediando processos de negociação com os trabalhadores, fiscalizando o cumprimento das normas legais, e criando incentivos e estimules, inclusive de natureza fiscal e creditícia, para as empresas que facilitem a educação básica dos seus empregados;

II - ações diretas do Estado, na condição de empregador, por si e por suas entidades vinculadas e empresas públicas.

Parágrafo único. O valor de bolsas de estudos ou outros benefícios educacionais, concedidos pelos empregadores a seus empregados, não será considerado, para nenhum efeito, como utilidade e parcela salarial, não integrando a remuneração do empregado para fins trabalhistas, previdenciários ou tributários.

$(\ldots)$

Capítulo XX

DAS DISPOSIÇÕES GERAIS E TRANSITÓRIAS 


\section{Projeto de Lei $\mathrm{n}^{\circ}$ 101, de 1993 ( $\mathrm{n}^{\mathrm{0}}$ 1.258, de 1988 na casa de origem)*}

Art. 114. Em cumprimento ao que dispõe o art. 60 do Ato das Disposições Constitucionais Transitórias: I - os Poderes Públicos mobilizarão os setores organizados da sociedade, em esforço conjunto para a eliminação do analfabetismo e a universalização do ensino fundamental;

II - as instituições públicas de ensino superior e médio que atuem na formação de profissionais de educação participarão, de forma específica, desse esforço conjunto, mediante as seguintes contribuições, dentre outras:

a) oferta intensiva de cursos de formação de alfabetizadores;

b) reciclagem de professores que atuam no ensino fundamental, na alfabetização e na educação de jovens e adultos;

c) elaboração de material didático adequado ao ensino fundamental, à alfabetização e a educação de jovens e adultos;

d) realização de projetos de pesquisa e de extensão, voltados para a solução de problemas ligados à alfabetização e à universalização do ensino fundamental;

e) cessão de espaço para programas de alfabetização;

f) liberação de tempo de professores, servidores e alunos, quando for o caso, as devidas compensações, para dedicação de determinados períodos de tempo, em cada semestre, a atividades diretas de alfabetização de jovens e adultos;

III - as empresas e os Poderes Públicos articular-se-ão para o desenvolvimento de programas de alfabetização de empregados adultos;

IV - os planos nacionais, estaduais e municipais de educação, nos próximos dez anos, isoladamente, no mínimo, 50\% (cinquenta por cento) das aplicações estabelecidas no art. 212 da Constituição Federal, às metas de erradicação do analfabetismo e de universalização do ensino fundamental;

V - o ensino médio, na modalidade Normal, receberá investimento para a sua expansão e melhoria qualitativa.

Art. 115. o primeiro Plano Nacional de Educação a ser elaborado na forma prevista no art. 105 desta Lei, deverá abranger período de cinco anos, a partir do ano seguinte ao da publicação da presente Lei, e observará os seguintes objetivos prioritários:

I - erradicação do analfabetismo;

II - universalização do ensino público fundamental, inclusive para jovens e adultos trabalhadores;

$(\ldots)$

VI - estimulo à formação para o trabalho, assegurada a educação básica comum;

VII - expansão e melhoria do ensino noturno em todos os níveis; (...).

\section{Lei no 9.394, de 1996 - atualizada até $2013^{* *}$}

\section{TÍTULO III}

Do Direito à Educação e do Dever de Educar

Art. $4^{\circ} \mathrm{O}$ dever do Estado com educação escolar pública será efetivado mediante a garantia de: 


\section{Lei $\mathrm{n}^{0}$ 9.394, de 1996 - atualizada até $2013^{* *}$}

I - educação básica obrigatória e gratuita dos 4 (quatro) aos 17 (dezessete) anos de idade,

$(\ldots)$

IV - acesso público e gratuito aos ensinos fundamental e médio para todos os que não os concluíram na idade própria; (Redação dada pela Lei n⿳ำ 12.796, de 2013)

(...)

VI - oferta de ensino noturno regular, adequado às condições do educando;

VII - oferta de educação escolar regular para jovens e adultos, com características e modalidades adequadas às suas necessidades e disponibilidades, garantindo-se aos que forem trabalhadores as condições de acesso e permanência na escola;

(...)

\section{Seção V}

Da Educação de Jovens e Adultos

Art. 37. A educação de jovens e adultos será destinada àqueles que não tiveram acesso ou continuidade de estudos no ensino fundamental e médio na idade própria.

$\S 1^{\circ}$ Os sistemas de ensino assegurarão gratuitamente aos jovens e aos adultos, que não puderam efetuar os estudos na idade regular, oportunidades educacionais apropriadas, consideradas as características do alunado, seus interesses, condições de vida e de trabalho, mediante cursos e exames.

$\S 2^{\circ}$ O Poder Público viabilizará e estimulará o acesso e a permanência do trabalhador na escola, mediante ações integradas e complementares entre si.

§3o A educação de jovens e adultos deverá articular-se, preferencialmente, com a educação profissional, na forma do regulamento. (Incluído pela Lei nº 11.741, de 2008)

Art. 38. Os sistemas de ensino manterão cursos e exames supletivos, que compreenderão a base nacional comum do currículo, habilitando ao prosseguimento de estudos em caráter regular.

$\S 1^{\circ}$ Os exames a que se refere este artigo realizar-se-ão:

I - no nível de conclusão do ensino fundamental, para os maiores de quinze anos;

II - no nível de conclusão do ensino médio, para os maiores de dezoito anos.

$\S 2^{\circ}$ Os conhecimentos e habilidades adquiridos pelos educandos por meios informais serão aferidos e reconhecidos mediante exames.

Fontes:* Diário do Congresso Nacional - Seção II - Sexta-Feira 28 de Maio de 1993. p. 4830-4874.

** http://www.planalto.gov.br/ccivil_03/leis/L9394.htm

Grifos nossos para evidenciar os termos que distinguem cada proposta.

As diferenças entre o PL resultante dos debates dos anos de 1988 a 1993, na Câmara dos Deputados, e o texto aprovado em 1996, se destacam primeiramente pela sua extensão. Havia uma preocupação com o detalhamento de responsabilidades e ações que deveriam ser assumidas pelos governos e pela sociedade civil no projeto original. Outra diferença significativa é a ênfase na caracterização específica de uma modalidade para 
trabalhadores, pensada nas condições e contradições do mundo do trabalho, mas também numa clara determinação de garantia de direitos aos jovens e adultos não escolarizados e seguiam sendo responsáveis pela produção da riqueza no País. Por último, cabe destacar que a ênfase dada a questão da alfabetização de jovens e adultos no PL nº 101, de 1993, no Capítulo das Disposições Gerais e Transitórias, colocava o tema como, efetivamente, de responsabilidade do poder público, enquanto coordenador de ações que buscassem o enfrentamento desta questão, tratando a alfabetização como parte integrante da formação básica dos trabalhadores.

Analisando o texto aprovado em 1996 e suas alterações até o presente, pode-se considerar uma dupla derrota para o campo da EJA. Primeiro, a clara perda de identidade de uma modalidade para trabalhadores, que deveria ser assumida por eles e pela sociedade como um todo, envolvendo o Estado como propositor da política educacional e o comprometimento dos segmentos de empregadores, sindicatos e instituições formadoras de educadores numa ação coordenada. Isto nos leva a segunda derrota, de um passado que não passou: a Lei nº 9.394, de 1996 é a reafirmação da perspectiva de suplência, expressa nos artigos 37 e 38, que poderia ter sido superada se a redação pudesse se concentrar em garantir as ofertas diferenciadas de educação básica para a modalidade.

Todavia, o ano de 1996 não foi marcado, para a EJA, apenas por essa infeliz alteração na LDB. Houve um movimento significativo de debates sobre a educação de adultos, mobilizado pela Unesco, em preparação à V Conferência Internacional de Educação de Adultos (V Confintea) ${ }^{5}$, que se realizou em 1997 em Hamburgo, na Alemanha. Esse debate também nos remete a uma outra parte do passado da EJA que não passou, que é a influência de organismos internacionais, em especial a Unesco, desde a I Confintea em 1947, nos rumos que a política educacional dos países-membros deveriam assumir.

Estas conferências internacionais demandam que os países-membros elaborem um diagnóstico da realidade da educação de adultos, que nos primeiros anos foram muito focados em dados de analfabetismo. No Brasil, em 1996, a elaboração deste diagnóstico abarcou informações bem abrangentes e foi coordenada pelo Ministério da Educação (MEC), que impulsionou a realização de encontros estaduais, regionais e um seminário nacional para discutir o tema. Como muitos sujeitos envolvidos na EJA já estavam mobilizados, desde os debates do Fórum em Defesa da Escola Pública, no processo de discussão do capítulo da educação na CF de 1988, e nos trâmites dos projetos de lei que se materializaram na Lei n 9.394, de 1996, esses encontros foram a oportunidade de trazer o contraditório à luz do dia. O documento brasileiro elaborado nesses encontros foi tão verdadeiro da crise que vivia a EJA no Brasil, naquele contexto de 1996, que nem o MEC o aceitou para apresentar na conferência regional, que reuniria as contribuições dos países da América Latina e Caribe ${ }^{6}$.

O que é relevante para a discussão nesse artigo, de todo esse contexto de 1996, é que, a partir dele, sujeitos históricos importantes na luta pela defesa da educação para todos 
se encontraram e passaram a unir esforços, a fim de buscar a concretização de políticas para o campo. Cabe um destaque para o segmento público, sobretudo o municipal, pois, em meados da década de 1990, havia secretarias municipais fazendo experiências inovadoras no campo da EJA, como por exemplo, São Paulo, as cidades do ABC Paulista, Porto Alegre, Belo Horizonte, Goiânia, entre outras; há que se considerar o envolvimento das universidades, que passaram a mobilizar os professores para envolver a temática da EJA nas atividades de ensino e pesquisa, já que sua atuação vinha se dando muito mais em nível de ações extensionistas; as organizações não governamentais (ONGs), que atuavam na EJA, sobretudo na formação de educadores e produção de material pedagógico; os sindicatos de profissionais da educação, que passam a ver a importância de pautar as especificidades da EJA em suas discussões com a categoria; o setor empresarial, representado pelo Sistema S, que já atuava há muitos anos em classes de alfabetização e educação de adultos; os organismos internacionais, sobretudo a Unesco e a Organização dos Estados Iberoamericanos (OEI), que já tinham um histórico de atuação na discussão da alfabetização e educação de adultos; os próprios educadores e educandos da EJA, que começaram a ter um espaço de diálogo com todos os atores que levavam à frente uma pauta, em que eles eram os principais interessados e dela precisavam assumir o protagonismo.

O encontro desses sujeitos coletivos, no mesmo momento em que aprova a Lei no 9.394, de 1996, faz com que esse balanço de 20 anos de LDB também seja um olhar sobre o que aconteceu no encontro. Como descrito acima, estamos tratando de governos e sociedade civil, numa construção de uma pauta que nem sempre é consensual e que demandou e demanda desses atores muita capacidade de diálogo, de negociação, mas também resultou e resulta em enfrentamentos e divergências nas posições, como será observado a seguir. Destacaria nesta reflexão, ainda, um importante movimento que surge desses sujeitos coletivos - os Fóruns de EJA ${ }^{7}$, organizados atualmente em todos os estados brasileiros e que passam a ter um papel importante de interlocução para a política de EJA, sobretudo a partir de 2004, quando o MEC passa a se reunir com o movimento e a participar efetivamente dos encontros nacionais por eles organizados $^{8}$. Esse debate intenso sobre como a EJA tenta, efetivamente, constituir-se política pública me encaminha à segunda parte de nossa reflexão.

\section{EJA: passos para se constituir a política pública de Estado}

Cabe aclarar dois conceitos que situam a EJA na ação do Estado, principalmente na perspectiva de constituir-se como política pública. O primeiro é o próprio conceito de Estado e o segundo é de políticas públicas. Compreendemos a realidade do Estado brasileiro a partir do conceito de Estado Ampliado (GRAMSCI, 2000). Olhando a realidade 
do seu país, o autor estabeleceu a relação entre dois tipos de sociedades que, para ele, compõem o Estado Ampliado. Trata-se da sociedade política e da sociedade civil, a primeira composta pelos aparelhos políticos e econômicos do Estado; a segunda, abrangendo os partidos políticos, os sindicatos, os movimentos sociais, as igrejas, o sistema escolar, tomando as escolas e também universidades, e o sistema de comunicação em geral, abarcando jornais, revistas, rádio, televisão, ou, como poderíamos dizer na atualidade, o próprio ambiente virtual multimídia interativo.

Esta concepção de Estado nos remete às políticas implementadas para EJA, nos últimos 20 anos, que resultaram da forte relação entre quem estava nos cargos de governos, portanto sociedade política, sejam eles no âmbito federal, estaduais, distrital e municipais, e quem estava à frente das várias expressões da sociedade civil. As políticas que se estabeleceram, então, resultaram da capacidade de diálogo ou não, da capacidade de formação de consensos ou não, da hegemonia das posições ou da coerção entre sociedade civil e sociedade política. Destacamos que, no caso da EJA, muitos dos militantes que atuavam na defesa da modalidade no âmbito da sociedade civil, ocuparam, ao longo desses 20 anos, cargos em governos municipais, estaduais, distrital e no governo federal, portanto, tiveram a oportunidade de vivenciar os desafios de estar num país, cuja política resulta de forte negociação nas relações que se travam no Estado Ampliado.

O termo política, conforme Azevedo (1997), refere-se a tudo que corresponde aos cidadãos e ao governo da cidade, aos negócios públicos. Vem do latim politicus e do grego politikós. Politicus exprime a situação de participação da pessoa que é livre nas decisões sobre os rumos da cidade. A palavra, pública é de origem latina, publica, e significa povo, do povo. Dessa forma, política pública, no sentido etimológico, diz respeito à participação do povo nas escolhas necessárias aos assuntos coletivos da cidade, do território. Conforme se deu o processo histórico brasileiro, essa participação assumiu aspectos diferentes, em um referido tempo e lugar, às vezes por representação direta ou indireta. De forma geral, no Brasil, o Estado constituiu-se em um autor fundamental na concretização de políticas públicas.

O processo de definição de políticas públicas para uma sociedade é marcado por conflitos de interesses e disputas de poder. A partir do surgimento de fatos sociais ou de movimentos de classe que, diante da sua importância política, econômica ou cultural, insistem com o Estado a organizar as medidas pertinentes que configurem a realização das necessidades levantadas. Por isso, voltamos à discussão inicial deste texto: uma lei é resultado de lutas e disputas de interesses, entre os que atuam no Estado Ampliado. Sintam-se nele todos os educadores, educandos, gestores e demais militantes da EJA, ali representados, participando das definições políticas de forma efetiva e consciente ou "de maneira desagregada e ocasional".

É dentro deste cenário de Estado Ampliado, com as relações que se estabeleceram entre a sociedade política e a sociedade civil, que chegamos à aprovação da Lei no 9.394 , 
de 1996. Como a aprovação desta lei não representava, exatamente, o conceito de EJA defendido por parte da sociedade civil, em que a escolarização estivesse pautada na aprendizagem e no conhecimento numa perspectiva emancipatória dos trabalhadores, o que se podia esperar era uma reação destes segmentos. Isto ocorreu antes mesmo do veredito final no Senado, quando em setembro de 1996 o, já referido, Seminário Nacional de Educação de Jovens e Adultos, realizado em Natal/RN, aprova o documento com o diagnóstico da EJA no Brasil na contramão do que desejava o MEC.

Desse contexto de final de 1996 até início de 2016, o que podemos afirmar é que a EJA ocupou um espaço na agenda da política educacional brasileira, na tentativa de se configurar como política pública, como nunca visto em toda a sua trajetória histórica9. Estamos longe da solução dos principais problemas de garantia do direito a educação para todas e todos os jovens trabalhadores do país e não se pode dizer que a Lei, efetivamente, alcançou seus objetivos, em termos da escolarização desta população. Todavia, as lutas travadas no âmbito das questões normativas, a busca pelo espaço específico da modalidade no sistema nacional de educação e o fortalecimento da sociedade civil organizada em torno dessa modalidade são inegáveis.

Vamos tentar demonstrar essas afirmações de forma mais objetiva, começando pelo que não conseguimos atingir que foi a garantia do acesso à escolarização da população jovem adulta, segundo os dados de demanda e matrícula nesses quase 20 anos, a partir de publicações oficiais, ou seja, dados da Pesquisa Nacional por Amostra de Domicílio (Pnad) do Instituto Brasileiro de Geografia e Estatística (IBGE) e do Censo Escolar, publicado pelo Instituto Nacional de Estudos e Pesquisas Educacionais Anísio Teixeira (INEP).

\section{Tabela 1 - Público da EJA 15 a 17 anos que não concluíram ensino fundamental e não estão frequentando em 2013}

\begin{tabular}{c|c|cc}
\hline Faixa etária & Total & \multicolumn{2}{c}{$\begin{array}{c}\text { Não frequentava escola e sem } \\
\text { Ensino Fundamental }\end{array}$} \\
\hline 15 a 17 anos & 10.642 .343 & 895.090 & $8,4 \%$ \\
\hline
\end{tabular}

Fonte: Pnad/IBGE (BRASIL, 2013)

O contexto que estamos analisando repõe um debate que foi intenso nos últimos dez $\operatorname{anos}^{10}$, sobre quem de fato são os sujeitos da EJA, por isso esses dados do quantitativo de adolescentes que ainda não concluíram ensino fundamental é tão relevante. Parte dos segmentos que atuam na EJA defendem a idade mínima de 18 anos para matrícula na modalidade, todavia, o sistema de ensino não se responsabiliza pelos quase $900 \mathrm{mil}$ que não estão em lugar nenhum e para aqueles que ainda buscam a escola, somente a EJA é dada como alternativa, ou, em alguns sistemas, como a expulsão dos alunos que "dão trabalho" no diurno. 
Tabela 2 - Público da EJA 18 anos e mais que não concluíram ensino médio e não estão frequentando em 2013

\begin{tabular}{|c|c|c|c|}
\hline Faixa etária & Total & \multicolumn{2}{|c|}{$\begin{array}{c}\text { Não frequentava escola e sem } \\
\text { Ensino Médio }\end{array}$} \\
\hline 18 a 29 anos & 38.367 .179 & 12.566 .266 & $32,8 \%$ \\
\hline 30 a 39 anos & 31.744 .482 & 13.961 .039 & $44,0 \%$ \\
\hline 40 a 49 anos & 27.203 .257 & 14.806 .852 & $54,4 \%$ \\
\hline 50 a 59 anos & 22.360 .197 & 14.680 .879 & $65,7 \%$ \\
\hline 60 anos ou mais & 26.279 .134 & 21.188 .921 & $80,6 \%$ \\
\hline
\end{tabular}

Fonte: Pnad/IBGE (BRASIL, 2013).

Os dados da população jovem, adulta e idosa são ainda mais alarmantes. Observe que a medida que o corte etário aumenta, cresce também o número de pessoas sem frequentar a escola. Um terço da juventude brasileira, que deveria demandar a Educação Superior, sequer concluiu a educação básica e não tem perspectiva de fazê-lo. Até para os mais céticos, cujo debate sobre o direito a educação deveria se concentrar na faixa etária de crianças e jovens, resulta um desconforto verificar que o país que se coloca entre as dez primeiras potências, em termos da economia mundial, tem mais da metade de sua população adulta, economicamente ativa, sem educação básica e sem perspectivas de concluí-la.

Esses dados resultam ainda mais alarmantes, quando comprovamos o esforço feito após a aprovação da LDB de 1996, que resultou num aumento de matrículas na EJA ${ }^{11}$, até aproximadamente o ano de 2006, seguido de quedas constantes em todas as etapas, até o ano de 2014.

\section{Quadro 2 - Matrícula na EJA em cursos presenciais - 1997-2014}

\begin{tabular}{|c|c|c|c|}
\hline Ano & Anos Iniciais do EF & Anos Finais do EF & Ensino Médio \\
\hline 1997 & 899.072 & 1.311 .253 & 390.925 \\
\hline 1999 & 817.081 & 1.295 .133 & 656.572 \\
\hline 2001 & 1.151 .429 & 1.485 .459 & 987.376 \\
\hline 2003 & 1.551 .018 & 1.764 .869 & 980.743 \\
\hline 2005 & 1.488 .574 & 1.906 .976 & 1.223 .859 \\
\hline 2006 & 1.487 .072 & 2.029 .153 & 1.345 .165 \\
\hline $2007^{*}$ & 1.187 .832 & 1.712 .130 & 1.279 .387 \\
\hline 2008 & 1.140 .979 & 1.883 .733 & 1.277 .078 \\
\hline 2009 & 1.053 .910 & 1.807 .147 & 1.224 .963 \\
\hline 2010 & 949.088 & 1.710 .346 & 1.133 .624 \\
\hline 2011 & 959.227 & 1.533 .237 & 1.085 .582 \\
\hline
\end{tabular}




\begin{tabular}{c|c|c|c}
\hline Ano & Anos Iniciais do EF & Anos Finais do EF & Ensino Médio \\
\hline 2013 & 873.673 & 1.370 .111 & 1.020 .571 \\
\hline 2014 & 814.377 & 1.301 .265 & 1.000 .010 \\
\hline
\end{tabular}

Fonte: Censo Escolar da Educação Básica. Inep. (BRASIL, 1997 a 2014).

* A partir de 2007, o Censo Escolar da Educação Básica passou a registrar informações por aluno, individualmente. Antes, eram contabilizados totais de alunos.

Esse total de cerca de pouco mais de três milhões de matrículas, registrados no ano de 2014, representa pouco, frente aos 78.099.047 brasileiros que a Pnad de 2013 informou que não possuíam educação básica e não estavam matriculados em nenhuma estratégia de escolarização. Portanto, esse é o pior cenário para chegar a 20 anos pós a LDB de 1996, quando esperávamos que a EJA se fortalecesse como política pública de Estado. Houve um processo de crescimento nos primeiros dez anos; há uma oscilação nos anos entre 2007 a 2009, justificada pelo próprio Inep, em função da mudança da metodologia de registro dos alunos; todavia, isto não explica nem justifica a queda contínua, que se observa desde 2010, em todas as etapas.

Para a compreensão do que ocorreu nesses 20 anos na matrícula da EJA, cabe considerar que os efeitos positivos dos dez primeiros anos têm relação com políticas implementadas para induzir os sistemas estaduais e municipais a investir na modalidade. O incremento na matrícula nos anos iniciais do ensino fundamental acompanha as ações de alfabetização, ligadas a continuidade da escolarização, que vão ocupar as principais discussões sobre os programas nacionais de alfabetização do período: Programa Alfabetização Solidária e Programa Brasil Alfabetizado. Ainda sobre essas matrículas, mas considerando o crescimento das matrículas dos anos finais do ensino fundamental na EJA, cabe retomar a discussão já realizada sobre o impacto negativo da implantação do Fundo de Manutenção e Desenvolvimento do Ensino Fundamental e Valorização do Magistério (Fundef) ${ }^{12}$, quando o presidente Fernando Henrique Cardoso, vetou na lei que criou este fundo, a contagem das matrículas da EJA e os mecanismos compensatórios de repasse de recursos a estados e municípios para apoiar as matrículas na modalidade (Programa Recomeço e Programa Fazendo Escola) ${ }^{13}$.

Os repasses compensatórios, embora tivessem estimulado, em alguma medida, a oferta da modalidade por parte dos sistemas estaduais e municipais, por outro lado, revelam um aspecto negativo da constituição da EJA como política pública de Estado, o da dependência quase total da indução financeira federal para que ela exista no âmbito das redes. No contexto de financiamento por programas, até 2007, cria-se uma falsa ideia de que a EJA está incorporada ao sistema público de ensino. Dizemos falsa, porque esse recurso aportado pelo governo federal não era suficiente para sustentar as demandas de contratação efetiva de educadores, que sustentem a abertura de turmas para EJA, do ensino fundamental e médio, em todos os estados e municípios. Isto é tão 
real, que quando o Fundef é substituído pelo Fundo de Manutenção e Desenvolvimento da Educação Básica e Valorização dos Profissionais da Educação (Fundeb) ${ }^{14}$, e, enfim as matrículas da EJA passam a ser consideradas nessa nova estratégia de financiamento para educação básica, o efeito nas matrículas dos estados e municípios é o da redução em todos os três segmentos de EJA ${ }^{15}$.

Mas, pode ser que mesmo nesse cenário ainda haja quem queira perguntar: Por que pensar a escola como necessária para esses jovens, adultos e idosos? Para responder a esta questão, retomamos o papel da escola no mundo moderno, que, na visão de Gramsci, expressa a própria complexidade do papel intelectual numa sociedade.

O enorme desenvolvimento obtido pela atividade e pela organização escolar (em sentido lato) nas sociedades que emergiram do mundo medieval indica a importância assumida no mundo moderno pelas categorias e funções intelectuais: assim como se buscou aprofundar e ampliar a 'intelectualidade' de cada indivíduo, buscou-se igualmente multiplicar as especializações e aperfeiçoá-las. (...) A escola é o instrumento para elaborar os intelectuais de diversos níveis. A complexidade da função intelectual nos vários Estados pode ser objetivamente medida pela quantidade de escolas especializadas e pela sua hierarquização: quanto mais extensa for a 'área' escolar e quanto mais numerosos forem os 'graus' 'verticais' da escola, tão mais complexo será o mundo cultural, a civilização, de um determinado Estado."(GRAMSCI, 2000, p. 19)

Olhando a realidade italiana nas duas primeiras décadas do século XX, Gramsci defende o espaço da escola como o lugar do desenvolvimento da "intelectualidade" e se refere à dicotomia trabalho manual e intelectual, muito presente nas reformas educacionais do seu país naquele contexto. Na realidade da EJA ainda vivenciamos essa dicotomia e temos que compreendê-la de forma mais ampla, tomando o sujeito como alguém que tem direito a um desenvolvimento equilibrado fisíco-emocional-mental. Concordando com Gramsci, a classe trabalhadora precisa, sim, OCUPAR a escola!!! para lutar pelo seu projeto de sociedade. No caso, a escola de EJA é lugar de Diálogo entre Trabalhadores, inclusive os professores, e isto faz toda diferença na educação de fato emancipatória.

Essa escola como lugar de "diálogo entre trabalhadores" nos reporta, dentre tantas políticas implementadas nos últimos $20 \operatorname{anos}^{16}$, às experiências de construção de currículo integrado entre formação geral e formação profissional, que se materializaram em programas como Saberes da Terra (BRASIL, 2005) e Proeja (BRASIL, 2007b), que em grande medida retomaram a perspectiva de uma escola para os trabalhadores, derrotada com a aprovação da LDB/96. Portanto, há ainda na dinâmica da escola, que resiste em atender aos limites das prescrições legais, sinais de construções alternativas de currículos, que buscam repor o sentido do conhecimento a serviço da transformação da realidade. Essa mesma perspectiva de resistência pode ser encontrada nas concepções de EJA presentes nos documentos finais da Conae de 2010 e 2014, que impactaram no texto aprovado do PNE 2014-2024, na Lei nº 13.005, de 2014. 
Isso indica que "a luta continua". Passos foram dados para que a EJA de fato não se encontre, em 2016, como estava em 1996. Todavia, não há como negar que seguimos tendo muito a fazer. A história não se repete, mas as contradições que movem a história nos provocam a olhar o vivido e retomar o curso. A conclusão desta reflexão tem que abrir espaço para nossas dúvidas. É o que tentamos fazer a seguir.

\section{Que o "pessimismo da inteligência" não imobilize o "otimismo da vontade"}

Nesta última parte, trago algumas das reflexões, porque os 20 anos que analisamos foram, pessoalmente, muito intensos. Não cabem aqui todas as emoções vividas, as lutas travadas, algumas delas vencidas, outras, não, mas creio que a conjuntura deste 2016, com o golpe parlamentar de Estado em curso, com os retrocessos vividos no último mês de governo ilegítimo, nos coloca a prova e nos mobiliza a refletir o que fizemos, e a buscar respostas para o que faremos. Comecei o artigo dizendo que o balanço de 20 anos só faria sentido para pensar os próximos 20.

Por tudo isso, divido aqui neste espaço mais reflexões do que constatações empíricas, numa tentativa de interlocução com os vários segmentos de que faço parte na EJA trabalhadores e/ou com quem compartilho um trabalho nessa área há cerca de 30 anos. Começo pensando nos educandos; gostaria muito de pensar com eles neste texto, mas, infelizmente, sei que serão pouquíssimos os que terão acesso a ele. E talvez seja essa a minha maior inquietação para com eles. O que fizemos nesses 20 anos de LDB de 1996 para que de fato eles fossem os protagonistas dessa luta pelo direito a educação, que é deles? Sei do esforço que os Fóruns de EJA para ter uma representação dos educandos nos seus espaços de mobilização, todavia, até que ponto essa mesma representação não termina por ser figurativa, pois quem conduz as pautas e representa de fato o movimento nas instâncias de decisão não são eles.

Ainda com os educandos, me pergunto até que ponto tudo o que acumulamos de propostas e consensos em relação ao que julgamos ser uma educação de qualidade de fato compartilha com seus sonhos, com sua visão de mundo e, sobretudo, consegue dar conta de um universo tão abrangente de sujeitos, que vão desde os adolescentes de 14 anos mais um dia, matriculados regularmente na EJA; passando pelos jovens das periferias das grandes cidades, muitos deles expulsos das escolas diurnas; pelos adultos e idosos, cada vez um público menor nas classes de EJA. Onde eles estão? Não fazem fila às portas das escolas pressionando por abertura de turmas, não fazem movimento de protesto pelos maus-tratos recebidos dentro e fora das escolas? Não denunciam os professores e gestores descomprometidos? Não reivindicam currículos mais adequados? Talvez se possa constatar que há desafios bem mais urgentes para travar, no que 
concerne a sobrevivência deles e dos seus, e que ainda não se dão conta de que a escola também é um espaço que deve se ocupar dessas e outras lutas.

E que dizer dos nossos educadores nesses 20 anos de LDB de 1996? Há uma mudança no perfil desses profissionais, alcançaram por sua incansável luta alguns parcos, mas valiosos direitos: piso salarial, carreira, formação... Todavia, essas conquistas estão longe de ser universalizadas e, de fato, assumidas pelos gestores municipais, distrital e estaduais. Ainda convivemos com monitores, voluntários e contratos precários de professores, atuando em classes de alfabetização até o ensino médio na EJA. Há ainda muito o que seguir lutando, sobretudo se estamos falando de profissionais que têm a sua frente um desafio diferenciado, que é trabalhar na modalidade EJA, e ainda carecemos de uma política de formação inicial e continuada, que considere efetivamente a modalidade, embora importantes esforços nesse sentido vêm sendo feitos por algumas universidades e sistemas de ensino.

Precisamente com os educadores que estão em classes de EJA, como concursados, que tiveram alguma formação sobre a modalidade, seja na licenciatura ou em cursos de formação continuada, há também que se perguntar: o que os faz estar na EJA? O que difere do trabalho que realizam com crianças e adolescentes, para o que fazem nessa modalidade? É possível ser um educador da EJA sem se preocupar onde estão os educandos, quem são, de onde vem, para onde pensam ir com essa escolarização? Por que não permanecem nas classes? O que o lado de fora das escolas tem a nos ensinar sobre como ser uma escola dos trabalhadores? É possível ser educador da EJA sem nenhum envolvimento com as lutas sociais que impactam sob a vida dos educandos e sobre a sua própria vida enquanto trabalhador? Como assumo o protagonismo da minha profissão frente as definições político-pedagógicas: sobre currículo, sobre material pedagógico, sobre metodologias de ensino-aprendizagem, sobre avaliação?

No diálogo com os gestores, o que mais nos interessa pensar é o quanto compreenderam o que de fato é a modalidade EJA nesses 20 anos. Saímos de uma visão gerencial, pragmática e tecno burocrática, muito consolidada com as experiências da Fundação Mobral e do Ensino Supletivo, para ir para onde? Será mesmo que saímos ou nos transportamos para outra sigla, levando na bagagem a marca da cultura escolar anterior? Não deixando de reconhecer aqui os esforços empreendidos pelas esferas: federal, estaduais, distrital e municipais, que tentaram imprimir um outro lugar para EJA, enquanto modalidade, seguimos mantendo uma lógica de cima para baixo. Ou seja, as gestões locais se movem à medida que o ente federal apresenta suas posições por portarias, decretos e leis, numa relação de parceria e adesão, sobretudo quando vêm acompanhadas de financiamento. A pergunta que se faz é: não tendo nenhuma cobrança legal e nenhum financiamento garantido por parte de "Brasília", qual é a proposta de EJA de cada município e estado brasileiro? Como ela foi construída? A que realidade ela responde? Podemos considerar que ter uma cópia quase fiel nos planos municipais, distrital 
e estaduais de educação ao plano nacional, em relação a EJA, é uma avanço diante da década passada em que esses planos sequer existiram ou saíram do papel? O que a gestão fará para que para na próxima década isso seja distinto?

Na mesma linha das dúvidas e indagações, chegamos a nós, pesquisadores, que, em sua maioria, vinculados às universidades, mas também oriundos de ONGs têm um papel fundamental na formação de educadores e na disseminação da produção sobre o campo da EJA. Que balanço podemos fazer dessas duas décadas? Seguramente somos mais hoje do que há vinte anos, estamos com um número significativo de pesquisas, desde a graduação, especializações, mestrado e doutorado, disponíveis para acesso e que se multiplicam em mais centenas de milhares de trabalhos apresentados em eventos, artigos e livros publicados. Ou seja, não deixa de ser um balanço otimista, mas o "pessimismo da inteligência" nos faz perguntar: a que serve tudo isso que fazemos? Correspondemos às exigências das agências de fomento, concorremos a editais, administramos recursos de toda ordem, cumprimos prazos, entregamos produtos... mas onde estão efetivadas as mudanças concretas que o conhecimento é capaz de produzir? Ou não estamos de fato produzindo um conhecimento que transforma a realidade, mas apenas a radiografa? Ou melhor dizendo, aprendemos a produzir diagnósticos por vezes sofisticados, porém o "doente" segue enfermo. Não cabe aqui uma interpretação salvacionista, nem da pesquisa, nem da formação que fazemos, elas por si só não mudam a realidade. Porém, quanto desse esforço empregado por todos nós, nas universidades e nas ONG, de fato tem assumido o compromisso ético-político de transformação da realidade investigada? Ocupamos nossas cargas horárias, preenchemos nossos relatórios, prestamos contas de financiamento e entregamos produtos a serviço de quem e de quê?

Por fim, onde estão todos os outros sujeitos da EJA? Há muitas perguntas para os sindicalistas, os empresários, os organismos internacionais, os movimentos sociais e populares do que pensam sobre 20 anos da EJA na LDB de 1996. Não são especialistas da área, mas parte deles poderia até ser sujeito da EJA. Podem dizer se perceberam algo de diferente, entre o que somos hoje e o que éramos no contexto da Ditadura Militar. Ocupamos com esses atores alguns cenários importantes na luta pelo direito a educação, foi assim na preparação das Conaes, na disputa pela aprovação do PNE 2014-2024, na participação no FNE, mas até que ponto há um consenso em relação ao papel estratégico da EJA na política educacional brasileira por parte desses segmentos? O espaço mais plural de participação desses segmentos como os destacados nos parágrafos anteriores é, sem dúvida o dos Fóruns de EJA, mas a esses também cabe perguntar: a que vêm? Passados também 20 anos de sua origem, quem são os fóruns hoje no dia a dia da luta pela EJA nos estados e municípios? O que se espera desse coletivo para os próximos 20 anos? 
Espero que tantas perguntas possam ser motivadoras de vários debates... Talvez se nada tivéssemos feito, nesses 20 anos de LDB, teríamos menos a perguntar. Ainda bem que não foi assim!

\section{Recebido em junho de 2016 e aprovado em agosto de 2016}

\section{Notas}

1 Frase utilizada por Antonio Gramsci em muitas das suas reflexões nos Cadernos do Cárcere, mas que são de autoria provável de Romain Rolland (Clamecy, 29 de janeiro de 1866 - Vézelay, 30 de dezembro de 1944) que foi um novelista, biógrafo e músico francês.

2 PAIVA (1981, 1982 a, 1982b, 1984, 1987).

3 HADDAD (1987).

4 FAVERO (1983, 2006); BRANDAO (1987); FREIRE (1987).

5 Conheça mais sobre a história das Confinteas lendo: http://unesdoc.unesco.org/images/0023/002305/230540POR.pdf

6 Sobre essa publicação não aceita pelo MEC e o processo que o Brasil viveu para se participar a V Confintea, acesse a seguinte publicação: http://forumeja.org.br/files/Vol\%2001_ed\%202_EducJovensAdultos.pdf

7 Sobre a história dos Fórum de EJA em âmbito nacional e nos estados acesse www.forumeja.org.br.

8 Sobre a participação dos Fóruns de EJA na agenda política do período de 2004 aos dias atuais, duas publicações podem ser indicadas: Revista do INEP Em Aberto nº 82 (Machado, 2009) e o mais recente documento posto em debate pelo MEC que faz um balanço da política de EJA, num Seminário realizado em abril de 2016, para avaliar os seis anos após a VI Confintea: Documento Nacional Preparatório à VI Conferência Internacional de Educação de Adultos / Versão atualizada Confintea Brasil+6.Brasília: MEC. Disponível em: http://unesdoc.unesco.org/images/0024/002446/244673POR.pdf . Acesso: junho de 2016.

9 Vide documentos indicados na nota 9 desse artigo.

10 Acesse o debate sobre idade na EJA no site http://forumeja.org.br/?q=node/925

11 As formas de organização da EJA na educação básica são diferenciadas, mas para de demonstrar dados de matrícula apresentamos a divisão de anos iniciais e finais do ensino fundamental e ensino médio que é a mantida pelo questionário do Censo Escolar do Inep.

12 Lei no 9424 de 24 de dezembro de 1996 (BRASIL, 1996b).

13 Dados financeiros desses repasses acesse: Documento Nacional Preparatório à VI Conferência Internacional de Educação de Adultos / Versão atualizada Confintea Brasil+6.Brasília: MEC. Disponível em: http:// unesdoc.unesco.org/images/0024/002446/244673POR.pdf . Acesso: junho de 2016.

14 Lei no 11.494 de 20 de junho de 2007 (BRASIL, 2007a).

15 Há muito o que aprendermos sobre financiamento da EJA, para estas reflexões sugiro aprofundar com a leitura de duas teses na área: Gouvea (2008), Volpe (2010) e Carvalho (2011).

16 Vide balanço dessas políticas no documento já indicado na nota 13. 


\section{Referências}

AZEVEDO, Janete M. Lins de. A educação como política pública. Campinas: Autores Associados, 1997.

BRASIL. Congresso Nacional. Projeto de Lei da Câmara no 101 de 1993 (nº 1258/88, na Casa de origem). Diário do Congresso Nacional, Brasília, p. 4830-4875, 28 maio 1993. Disponível em: <http:// legis.senado.gov.br/diarios/BuscaDiario?datSessao=27/05/1993\&tipDiario=1>. Acesso em: 06 set. 2016.

. Lei no 9.394, de 20 de dezembro de 1996. Estabelece Diretrizes e Bases da Educação Nacional. Brasília, 1996a. Disponível em: <http://www.planalto.gov.br/ccivil_03/leis/L9394.htm>. Acesso em: 06 set. 2016.

. Lei n⿳0 9.424, de 24 de dezembro de 1996. Dispõe sobre o Fundo de Manutenção e Desenvolvimento do Ensino Fundamental e de Valorização do Magistério, na forma prevista no art. 60, § 7ำ do Ato das Disposições Constitucionais Transitórias, e dá outras providências. Brasilia, $1996 \mathrm{~b}$. Disponível em: <http://www.planalto.gov.br/ccivil_03/leis/L9424.htm>. Acesso em: 06 set. 2016.

. Ministério da Educação. Instituto Nacional de Estudos e Pesquisas Educacionais Anísio Teixeira. Censo Escolar da Educação Básica. Brasília, 1997-2014.

. Ministério da Educação. Secretaria de Educação Continuada Alfabetização e Diversidade. Programa Nacional de Educação de Jovens e Adultos, Integrada com Qualificação Social e Profissional para Agricultores Familiares. Saberes da Terra. Brasília, 2005.

. Ministério da Educação. Secretaria de Educação Profissional e Tecnológica. Programa de Integração da Educação Profissional com a Educação Básica na Modalidade de Educação de Jovens e Adultos - PROEJA. Documento Base. Brasília, 2007a.

. Lei n⿳0 11.494, de 20 de junho de 2007. Regulamenta o Fundo de Manutenção e Desenvolvimento da Educação Básica e de Valorização dos Profissionais da Educação - FUNDEB, de que trata o art. 60 do Ato das Disposições Constitucionais Transitórias; altera a Lei $\mathrm{n} \underline{\mathrm{O}}$ 10.195, de 14 de fevereiro de 2001; revoga dispositivos das Leis $n^{\underline{o s}}$. 9.424, de 24 de dezembro de 1996, 10.880, de 9 de junho de 2004, e 10.845, de 5 de março de 2004; e dá outras providências. Brasilia, 2007b. Disponível em: <http://www.planalto.gov.br/ccivil_03/_ato2007-2010/2007/lei/111494.htm>. Acesso em: 06 set. 2016.

. Ministério do Planejamento, Orçamento e Gestão. Instituto Brasileiro de Geografia e Estatística. Pesquisa Nacional por Amostra em Domicílios. Brasilia, 2013.

. Lei no 13.005, de 25 de junho de 2014. Aprova o Plano Nacional de Educação - PNE e dá outras providências. Brasília, 2014. Disponível em: <http://www2.camara.leg.br/legin/fed/lei/2014/lei-1300525-junho-2014-778970-publicacaooriginal-144468-pl.html>. Acesso em: 08 set. 2016.

- Ministério da Educação. Secretaria de Educação Continuada, Alfabetização, Diversidade e Inclusão. Documento Nacional Preparatório à VI Conferência Internacional de Educação de Adultos: versão atualizada Confintea Brasil+6. Brasília, 2016. Disponível em: <http://unesdoc.unesco.org/ images/0024/002446/244673POR.pdf>. Acesso em: 05 set. 2016.

BRANDÃO, Carlos Rodrigues. (Org). A questão política da educação popular. São Paulo: Brasiliense, 1987.

CURY, Carlos Roberto Jamil. Direito a Educação: direito à igualdade, direito à diferença. In: Cadernos de Pesquisa, n. 116, p. 245-262, jul. 2002. 
CARVALHO, Marcelo Pagliosa. As políticas para Educação de Jovens e Adultos nos governos Lula (2003-2010): incongruências do financiamento insuficiente. 2011. Tese (Doutorado) - Faculdade de Educação da Universidade de São Paulo, São Paulo, 2011. Disponível em: http://www.teses.usp.br/ teses/disponiveis/48/48134/tde-20012012-094046/pt-br.php. Acesso em: 06 set. 2016.

FAVERO, Osmar (Org.). Cultura popular educação popular: memória dos anos 60. Rio de Janeiro: Graal, 1983.

Uma pedagogia da participação. São Paulo: Autores Associados, 2006.

FREIRE, Paulo. Pedagogia do oprimido. São Paulo: Cortez, 1987.

GOUVEA. Andrea Barbosa. Políticas e financiamento na EJA: as mudanças na política de financiamento da educação e possíveis efeitos na EJA. In: EccoS - Revista Científica, São Paulo, v. 10, n. 2, p. 379-395, jul./dez. 2008.

GRAMSCI, Antonio. Cadernos do cárcere. Rio de Janeiro: Civilização Brasileira, 1999 e 2004a. V. 1.

Cadernos do cárcere. Rio de Janeiro: Civilização Brasileira, 2000. V. 2.

HADDAD, Sérgio. Ensino supletivo no Brasil: o estado da arte. Brasília: MEC/INEP/CEDI, 1987.

MACHADO, Maria Margarida (Org.) Educação de jovens e adultos. Em Aberto, Brasília, Inep, v. 22, n. 82, p. 1-147, Nov. 2009.

PAIVA, Vanilda P. Perspectivas e dilemas da educação popular. Rio de Janeiro: Graal, 1984.

Educação popular e educação de adultos. São Paulo: Loyola, 1987.

PAIVA, Vanilda P. Mobral: um desacerto autoritário - 1aㅡ parte: o Mobral e a legitimação da ordem. Síntese. Rio de Janeiro, v. 8, n. 23, p. 83-114, set./dez. 1981.

. Mobral: a falácia dos números (Um desacerto autoritário II). Síntese. Rio de Janeiro, v. 9, n.24, p. 51-72, jan./abr. 1982a.

Estratégias de sobrevivência do Mobral (Um desacerto autoritário III). Síntese. Rio de Janeiro, v. 9, n. 25, p. 57-91, maio/ago. 1982b.

VOLPE, Geruza Cristina Meirelles. O financiamento da educação de jovens e adultos no período de 1996 a 2006: farelos de migalhas. 2010. Tese (Doutorado) - Faculdade de Educação na Universidade de Campinas, São Paulo, 2010. 